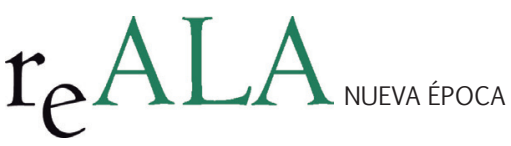

REALA, n Extraordinario, enero 2015 ISSN: 1989-8975

DOI: http://dx.doi.org/10.24965/reala.voiExtra.10220

\title{
Génesis y finalidad de la reforma local
}

Manuel Arenilla Sáez

Catedrático de Ciencia Política y de la Administración. Universidad Rey Juan Carlos. Director del INAP

manuel.arenilla@urjc.es

\section{Resumen}

La Administración local no ha ocupado tradicionalmente un lugar central en el sistema político-administrativo español, lo que contrastas con la gran vitalidad de los gobiernos locales a partir de la década de los 80 del pasado siglo, especialmente en las grandes y medianas ciudades españolas. Estas asumieron una serie de nuevas responsabilidades a la vez que se estaban consolidando las comunidades autónomas. El resultado han sido las duplicidades, solapamientos e ineficiencias que reducen los derechos de los ciudadanos y que la actual crisis ha hecho que se vean como inaceptables. Esta situación debe ser solventada a través de mecanismos de coordinación, integración y cooperación entre los diversos poderes territoriales y los actores que actúan en la comunidad. La Ley 27/2013, de 27 de diciembre, de racionalización y sostenibilidad de la Administración Local se ha diseñado para preservar el futuro de la Administración local y su estabilidad financiera y competencial; esto es, para garantizar un conjunto de derechos de los ciudadanos respecto a sus municipios.

\section{Palabras clave}

Reforma local, España, eficiencia, coordinación territorial

\section{Genesis and purpose of the Local Reform}

\section{Abstract}

Local Government has not traditionally occupied a central place in the Spanish political-administrative system. This is in contrast to the great vitality of local governments since the 1980's, particularly in large and medium-sized Spanish cities. They took on great new responsibilities at a time when the autonomous communities were being consolidated. The result has been the duplicities, overlappings and inefficiencies that restrict the rights of citizens. The current crisis has demonstrated that this is unacceptable. This situation must be resolved by means of systems of coordination, integration and cooperation between the various territorial governments and all those who operate in the community. The Act 27/2013, of the 27th of December for the rationalization and sustainability of the Local Administration has been designed to preserve the future of the local Administration, its power and financial stability; to guarantee a set of rights for citizens with respect to their municipalities.

Key words

Local Government reform, Spain, efficiency, territorial coordination 


\title{
SUMARIO
}

\author{
1. LA CONSTITUCIÓN DE NUESTRO SISTEMA LOCAL. 2. PRINCIPIOS Y BASES DE LA REFORMA. 3. LOS \\ PROBLEMAS Y SUS RESPUESTAS. 4. REFLEXIONES FINALES. 5. BIBLIOGRAFÍA.
}

\section{LA CONSTITUCIÓN DE NUESTRO SISTEMA LOCAL}

La división del poder en el territorio es una de las cuestiones que más controversias suscita en la conformación de los Estados. Se trata de articular las distintas unidades políticas y sociales existentes en una sociedad con el fin de lograr la integración y la cohesión social y la unidad y estabilidad del Estado. A la vez, es preciso determinar los niveles territoriales y el poder que va a ostentar cada uno de ellos y la manera en la que se van a relacionar. Las tensiones y alternativas que surgen en cada una de estas cuestiones afloran con motivo de cada crisis institucional o cambio constitucional, como puede observarse en España desde 1812 hasta nuestros días.

En los dos últimos siglos de nuestra historia, el modelo prevalente de la distribución del poder en el territorio es el de un centro con atribuciones en la formulación de las políticas públicas y la ejecución de las políticas más estructurantes de la sociedad. Cuando se ha optado por un modelo cuasi federal como el actual o el «integral» de la II República, las unidades regionales han compartido esa ejecución y han intervenido en la fase de formulación de las políticas públicas. En general, la Administración local española, más allá de unos breves periodos de tiempo que apenas tuvieron consecuencias prácticas, ha tenido un papel subordinado o complementario, menor, al poder o los poderes centrales en el diseño constitucional.

El estudio de los fundadores de nuestro modelo local, dominado claramente por los liberales doctrinarios y conservadores, mostrará una serie de rasgos que todavía hoy, con las lógicas transformaciones, podemos percibir. La primera nota es la necesidad de la división territorial, que para León de Arroyal en 1789 «es el cimiento de la buena administración" y que debía de ser uniforme y en provincias (Arroyal, 1968: 189). En esta misma idea incidirá Colmeiro (1995: 48): «La primera condición de un buen sistema administrativo es una acertada división territorial o la distribución de la acción administrativa en cierto número de esferas particulares que juntas se muevan en armonía y en virtud de un solo impulso». Sigue en esto a Bonnin (1834: 57), que señaló: «La división política del territorio, medida que precede á todas las demas en la en la institucion comunal, es una medida constitucional y la llave del edificio social».

La segunda nota es la necesidad de que los ministerios contaran con presencia en el territorio a través de aparato propio. Así, Javier de Burgos, artífice de la división provincial y del diseño inicial de la Administración periférica del Estado, señalaría que «el primer objeto de la division territorial es facilitar al que manda el conocimiento de las necesidades y de los recursos de un país; y este conocimiento, que es una necesidad para el gobierno y una garantia para los súbditos, se adquiere tanto mas facilmente cuanto mayor sea la inmediacion ó el contacto del administrador con el administrado» (Burgos, 1820). Esta misma idea la expresa al declarar que una de las bases de la Hacienda, y con ello del Estado, es «Hacer una division territorial arreglada y uniforme, que permita estender al rincon mas oscuro de cada distrito la accion benéfica de la administración» (Burgos, 1820). Pudiera caber alguna duda sobre el alcance del término «administración», pero queda claramente despejada en sus textos y en la siguiente nota.

La tercera nota es el otorgamiento de un papel secundario a la Administración local y dependiente o subordinado del centro, sea este estatal o regional. El origen de este planteamiento se encuentra en el liberalismo doctrinario. Este contrapone la Administración local con la activa, la propia del Gobierno central. Sus principales teóricos afirman: «Como consecuencia de lo arriba sentado, habrá la Administración central de estar revestida de las necesarias facultades para obligar, lo mismo a los alcaldes que a los Ayuntamientos, a encerrarse en el círculo de sus respectivas funciones y a llenarlas según las leyes» (Oliván, 1954: 157); «La ejecución debe estar siempre a cargo de la Administración activa, o sea, del gobernador responsable, pues que las corporaciones no son propias para operaciones activas» (Oliván, 1954: 149); «El alcalde ejerce sus funciones de la autoridad administrativa, bajo la dependencia inmediata del jefe de la Administración provincial» (Burgos, 1978: 112); «La ley no debe conferirles [a las diputaciones provinciales] atribuciones que puedan convertirlas en instrumentos de pasiones políticas» (Burgos, 1978: 163); «Pero en rigor y tales como estas corporaciones [las diputaciones provinciales] se hallan establecidas en la actualidad no debemos empeñarnos demasiado en la cuestion, pues en efecto, han perdido gran parte de su importancia y no pueden ofrecer grandes obstáculos á la administración activa, ni estorbar su marcha libre, uniforme y desembarazada» (Sáinz de Andino, 1982: 552). 
La cuarta nota es el mantenimiento de una relación directa entre el Gobierno y la Administración General del Estado y los gobiernos locales, como se ha visto en algunas de las citas anteriores. Esto sucede en la actualidad, incluso aunque las comunidades autónomas sean las que llenan de contenido funcional la mayoría de la actividad local y ocupen la centralidad en el territorio. No obstante, el nivel central estatal sigue en la actualidad manteniendo amplios poderes en lo que respecta a la regulación básica del régimen jurídico local, de su personal, especialmente de los habilitados nacionales, y a la financiación. Este último aspecto se ha visto fuertemente reforzado en la actual crisis mediante el despliegue de distintos instrumentos de control financiero por parte de la Administración General del Estado destinados a los entes locales.

Podemos afirmar así que nuestro sistema cultural político-administrativo se fundamenta en gran parte en un modelo de distribución del poder en el territorio en el que el ámbito local ocupa una posición débil en el conjunto del Estado, tanto en términos competenciales como en los presupuestarios y financieros. Esto contrasta con las profundas transformaciones que ha experimentado la sociedad española en las últimas décadas y con las demandas crecientes de los ciudadanos, especialmente en términos de fortalecimiento democrático. Indudablemente, el cauce natural de manifestación de las nuevas demandas y necesidades ciudadanas es el ámbito municipal, especialmente en las medianas y grandes ciudades españolas. Además, existen una serie de competencias que se residencian de manera estructural en el ámbito municipal, singularmente las de servicios sociales (Arenilla, Pérez y Romera, 2014).

La solución a una mayor descentralización local, que se viene reclamando por los responsables políticos locales desde mediados de los noventa del pasado siglo, no vendrá solo de la redefinición del marco competencial, sino que debe ser el resultado de un cambio sustancial de cultura que oriente la actuación de los poderes públicos hacia el nivel más próximo al ciudadano siguiendo principios y criterios de subsidiariedad, de eficacia, de gestión integrada y cooperativa, de capacidad y de sostenibilidad. Esto significa repensar el reparto de poder entre los niveles territoriales implicados. La nueva ley local viene a remover la distribución preexistente de ese poder e introduce una serie de instrumentos que empujan y favorecen el diálogo entre el ámbito autonómico y el local. Al nivel central estatal y autonómico corresponde ahora que la gestión pública se acerque al vecino de una manera efectiva.

\section{PRINCIPIOS Y BASES DE LA REFORMA}

La aprobación de la Ley 27/2013, de 27 de diciembre, de racionalización y sostenibilidad de la Administración Local fue compleja; prueba de ello fueron los más de treinta borradores y anteproyectos de ley elaborados a lo largo del casi año y medio de tramitación previa al Consejo de Ministros. A pesar de las muchas variaciones efectuadas en los textos, hay cuatro principios que se mantuvieron invariables. El primero de ellos es la necesidad de evitar los solapamientos y duplicidades de las competencias municipales con las de las comunidades autónomas y que se concretó en la expresión «una Administración, una competencia». El segundo pone el énfasis en la centralidad del ciudadano como receptor de los servicios públicos y en la garantía de la igualdad de los ciudadanos en el acceso a los mismos, independientemente del lugar de residencia. El tercer principio es la preservación de ese acceso desde el punto de vista financiero mediante la garantía de la solvencia y la sostenibilidad municipal, con el fin de que las actividades y servicios municipales ofertados puedan constituirse en verdaderos derechos de los ciudadanos. El cuarto principio son en realidad dos: la transparencia y su reverso, la rendición de cuentas. Se produce un verdadero empoderamiento al ciudadano al considerar que la actividad pública debe prestarse rindiendo cuentas y con la máxima transparencia y rigor en la gestión de los recursos públicos.

Estos principios alimentan una serie de transformaciones en el modelo del gobierno local en España que se sustenta en unas bases. La primera afecta al sistema de relaciones intergubernamentales al impulsar la reforma la colaboración necesaria en la gestión de las competencias municipales de los gobiernos de las comunidades autónomas, las diputaciones provinciales y los ayuntamientos, especialmente en los municipios de menos de 20.000 habitantes. Se busca con ello fortalecer la cooperación y la confianza inter-institucional.

La segunda base vincula la eficiencia con los derechos de los ciudadanos. La falta de logro efectivo de la primera merma los segundos. La ley adapta en el ámbito local la Ley Orgánica 2/2012, de 27 de abril, de Estabilidad Presupuestaria y Sostenibilidad Financiera con el fin de corregir la insuficiente atención que algunas Administraciones locales han otorgado tradicionalmente a los aspectos financieros y presupuestarios y a la estabilidad y continuidad de los servicios que prestan.

La tercera base de la nueva ley es la introducción de medidas efectivas de transparencia y de responsabilidad. Se fortalece la publicidad y la información de la gestión pública y se otorga más poder a los ciudadanos y a otras 
instituciones públicas para que controlen mejor el ejercicio de la acción política local. A la vez, se incrementa la responsabilidad y la rendición de cuentas de los poderes locales a los organismos estatales o autonómicos que tienen competencias en materia financiera, y también a los ciudadanos. Se persigue con ello mejorar la legitimidad de nuestras instituciones públicas y la aceptación de sus integrantes.

La última base es la defensa en la ley de la profesionalización de la Administración local, en concreto de los funcionarios de Administración local con habilitación de carácter nacional y especialmente de la función interventora. Se recupera su selección por la Administración General del Estado, en concreto por el Instituto Nacional de Administración Pública, y se incrementa su diferenciación y defensa frente al ámbito político o a cualquier otro tipo de consideraciones ajenas a su transcendente función pública.

Estas cuatro bases están diseñadas para asentar sobre ellas una Administración local más sólida y sostenible, mejor orientada al ciudadano y a sus necesidades, pues no hay que olvidar que son los ciudadanos los que sustentan el sistema político-administrativo y le otorgan su legitimidad.

\section{LOS PROBLEMAS Y SUS RESPUESTAS}

Existe una alta coincidencia entre los operadores del régimen y del gobierno local en el diagnóstico sobre sus disfunciones; claro es que esta coincidencia no se extiende a sus posibles soluciones. Estas van a depender de cuál sea el modelo que se adopte de distribución y articulación del poder en el territorio.

El hecho de que la regulación local después de la Constitución de 1978 se efectuase cuando ya había comenzado el proceso de transferencias a las comunidades autónomas, pero que no se supiese cuál iba a ser la configuración definitiva del modelo autonómico, determinó en buena parte las duplicidades y solapamientos competenciales entre el ámbito municipal y el autonómico. Este hecho se vio favorecido por la concepción universalista de los intereses y competencias de nuestros municipios en la Ley 7/1985, de 2 de abril, Reguladora de las Bases del Régimen Local (LRBRL); de aquí que se detectara pronto la necesidad de articular mejor los niveles subnacionales, incluyendo el ámbito provincial que, salvo significativas excepciones en las últimas décadas, apenas ha tenido un papel relevante en la solución de los problemas derivados del inframunicipalismo.

La Ley 27/2013, de 27 de diciembre, de racionalización y sostenibilidad de la Administración Local (LRSAL) establece la priorización de las competencias y su vinculación con la financiación. Como principio general, los municipios prestarán servicios no obligatorios a sus ciudadanos cuando los obligatorios estén garantizados, no existan duplicidades con las competencias autonómicas y se cumplan los criterios de estabilidad presupuestaria y sostenibilidad financiera (que incluyen aspectos como el nivel de deuda, la morosidad o el pago a proveedores). La gradación competencial sitúa a la cabeza las básicas u obligatorias, luego las delegadas y finalmente las competencias no obligatorias. Además, la vinculación entre competencia y su correspondiente financiación se acentuará en el futuro al anunciarse en la ley la conexión, por primera vez, entre el sistema de financiación autonómica y el de las Haciendas Locales.

Por otro lado, la sociedad de 1985 era menos compleja que la actual hasta el punto de que hoy lo que resulta pertinente es hablar de gobiernos locales más que de Administraciones locales, significando con ello que para resolver las principales demandas y necesidades sociales es preciso la concurrencia de actores sociales, gubernamentales, empresariales y los propios ciudadanos que forman redes de políticas y de actores (Arenilla, 2011) que se complican conforme lo hacen las comunidades de las que surgen.

El inframunicipalismo aparece como una característica llamativa de nuestro sistema local. En las tres últimas décadas no ha existido una voluntad real por parte de las comunidades autónomas de resolverlo ni tampoco de incentivar la fusión de pequeños municipios. El resultado de estos años ha sido el incremento de la planta local por segregación municipal. Finalmente, cuando se han adoptado medidas de integración o cooperación su efectividad se ha dejado al acuerdo entre las partes.

La respuesta que se da al inframunicipalismo en la reforma local parte de que el problema no es el número de entidades locales, sino el efecto que esto produce en el ciudadano. Se enfoca el problema desde el derecho de los ciudadanos a una buena Administración, a la recepción de servicios en condiciones de igualdad, independientemente del lugar en el que se reciban; es decir, el derecho a la prestación igualitaria de servicios en todo el territorio nacional, con un mismo nivel de calidad y a un coste similar. La insuficiente escala para la prestación de 
actividades y servicios públicos es una de las causas principales de la desigualdad de los ciudadanos en el acceso a los mismos. En definitiva, se pone el énfasis en el receptor de la acción pública, en el ciudadano, y en la eficiencia, al entender que cuando esta no se produce, se está restando derechos al ciudadano, especialmente en las pequeñas localidades.

La reforma diferencia entre el municipio como núcleo de población, como núcleo que presta servicios y como núcleo de la representación democrática, de tal manera que se mantiene el primero al entender que el ciudadano tiene derecho a percibir su territorio en términos de identidad histórica y social, pero que de ahí no debe derivarse que sea el municipio el que deba prestarle todos los servicios que hasta ese momento se atribuían a la entidad local. A la vez, defiende la necesidad de que siga siendo el lugar de representación democrática, con el fin de que se conforme en el municipio, independientemente de su dimensión, la voluntad de los vecinos y esta pueda expresarse en las instituciones en las que se garanticen efectivamente sus derechos como receptores de bienes, servicios y actividades municipales. Si se piensa detenidamente, esto es lo que viene sucediendo en buena parte de los municipios en España desde hace tiempo, ya que muchos de sus servicios son prestados en la actualidad por entidades supramunicipales o por las comunidades autónomas. Lo que hace la ley es plasmar esa realidad, formalizarla y establecer mecanismos de gestión cooperativa no voluntarios, principalmente entre los ayuntamientos y las diputaciones provinciales para los municipios de menos de 20.000 habitantes.

La reforma, además, redefine la planta municipal. Establece que para que en el futuro se constituya un municipio deberá tener un mínimo de 5.000 habitantes; ser financieramente sostenible; contar con recursos suficientes para el cumplimiento de sus competencias municipales; y que no disminuya la calidad de los servicios que venga prestando. Las entidades locales menores existentes antes de la entrada en vigor de la LRSAL mantienen su estatus, mientras que las de nueva creación carecerán de personalidad jurídica, considerándoseles entes desconcentrados de los municipios. Finalmente, la reforma determina que la Administración General del Estado promueva e incentive la fusión voluntaria de municipios atendiendo a criterios geográficos, sociales, económicos y culturales.

La tradicional falta de cultura cooperativa en España desembocó en la existencia de casi 5.700 entidades del sector público local en 2007 que, además, se solapaban en buena parte con la Administración matriz y con otras Administraciones públicas, especialmente las comunidades autónomas. Se hacía necesario, por tanto, establecer una reforma que lograse la sostenibilidad de los derechos de los ciudadanos derivados de la oferta de bienes y servicios de los gobiernos locales sobre la base de la eficiencia. A finales de 2013, la cifra anterior se había rebajado en 962 entes, previéndose una reducción mayor en 2014.

La LRBRL partía de la idea de que ninguna de las necesidades de los vecinos ni nada de lo que sucediera en el municipio era, en principio, ajeno a la gestión del Ayuntamiento. La combinación de esta idea con la falta de cultura cooperativa y con un inadecuado, cuando no irreal, tratamiento de los ingresos ordinarios y del gasto público dio lugar a las cifras señaladas de entes públicos, a las duplicidades y a la inviabilidad de muchos entes locales. El problema de fondo es que se ha confundido «competencia» con «incumbencia». Es claro que al Ayuntamiento le incumbe lo que le afecte a sus vecinos, pero esto no significa que deba tener las competencias necesarias para resolverlo, ya que, en muchos casos, corresponde a otro nivel administrativo el hacerlo; con este nivel habrá de establecer los cauces de colaboración, cooperación o coordinación o los mecanismos de delegación necesarios, o deberán establecerse sistemas de cogestión con otros municipios. Ser consciente de los problemas de los ciudadanos no debe conllevar asumir directamente su resolución mediante gestión propia o indirecta. Se obvia, de esta manera, la gestión cooperativa y se profundiza en el particularismo y la desconfianza institucional.

La combinación de los fenómenos anteriores da lugar a la dilución de responsabilidades políticas, ya que al ciudadano le resulta difícil asignarlas con claridad ante la pléyade de organismos territoriales existentes en nuestro país, que suman alrededor de 13.000. Si no es posible atribuir claramente las responsabilidades políticas por parte de los ciudadanos, esto desincentivará la rendición de cuentas y la democracia se resentirá. Además, la rendición de cuentas ha sido deficitaria, especialmente en mancomunidades, agrupaciones de municipios y entidades locales menores. La solución propuesta por la reforma aprobada es reducir el número de organismos, impedir su crecimiento en el futuro, establecer mecanismos voluntarios y no voluntarios de cooperación entre los entes territoriales y reforzar los mecanismos ligados a la estabilidad presupuestaria y la sostenibilidad financiera. Uno de los efectos que este tipo de medidas ya ha producido es el incremento notable en el cumplimiento de la obligación de comunicación de la liquidación presupuestaria en las entidades locales. 
El anterior modelo ha producido la debilidad democrática de los municipios y la aparición y extensión de los servicios impropios; a la vez que estos ponen de manifiesto el desajuste del sistema competencial. Sin embargo, algunos de los servicios impropios pueden considerarse estructurales al venirse prestando tradicionalmente por los municipios a cargo de sus propios medios financieros, como es el caso de los servicios sociales (Arenilla, Pérez y Romera, 2014: 217 y ss.). Esta realidad debe forzar el entendimiento entre los distintos niveles territoriales y una reordenación de los recursos.

La atribución impropia de competencias por los municipios, en ocasiones, se ha visto refrendada por las leyes autonómicas sin que estas hayan previsto la financiación correspondiente. La reforma reduce las competencias municipales al delimitarlas de las autonómicas, pero no busca que se generen vacíos competenciales ni el abandono de servicios esenciales de la comunidad, antes bien, aboca a la búsqueda de acuerdos entre las comunidades autónomas y los entes locales, a la vez que refuerza el papel supramunicipal de las diputaciones provinciales.

El panorama tradicional descrito, alimentado por la posición que ocupan históricamente los gobiernos locales en el sistema político-administrativo, ha desembocado en una debilidad financiera que se exacerba en momentos de crisis como los actuales. Esta debilidad se alimenta por la reducida escala de la prestación de los servicios, que lleva a que el sobrecoste por recibir un mismo servicio en un municipio pequeño respecto a uno mediano o grande —una media de casi tres veces más_ haya de ser medido en términos de ineficiencia y de reducción de derechos de los ciudadanos. La debilidad también se manifiesta en el hecho de que una parte significativa de la financiación local es finalista a través de los convenios, principalmente autonómicos. La reforma efectuada, además del ajuste de competencias y la potenciación de las diputaciones provinciales, establece la obligatoriedad de la financiación completa de los convenios firmados con las comunidades autónomas y la posibilidad de que los municipios compensen el incumplimiento de pago de estas con las deudas autonómicas.

La combinación de la entrada en vigor de la Ley Orgánica 2/2012, de 27 de abril, de Estabilidad Presupuestaria y Sostenibilidad Financiera con el anuncio de la reforma local y el conjunto de medidas dispuestas para la Administración local por el Gobierno de España a partir de 2012 (plan de racionalización, Fondo de Liquidez Autonómica, pago a proveedores, incremento del IBI, adelanto de la participación en los ingresos del Estado, retraso en el reintegro correspondiente a los ejercicios 2008 y 2009, incremento de la financiación, planes de ajuste) produjo que se pasase de un déficit en la entidades locales del 0,39\% del PIB al 0,52\% de superávit de 2013; una reducción del gasto entre 2011 y 2012 de 4.233 millones de $€$, o el 9,2\% sobre el gasto de 2011; y una reducción de efectivos entre enero de 2012 y enero de 2014 del 6,10\%. Finalmente, el número de corporaciones que presentaron un saldo presupuestario positivo pasó de 3.874 en 2010 a 6.413 en 2013.

Es necesario señalar que el paso de una situación de déficit a otra de superávit no ha sido, en la mayoría de los casos, a iniciativa de la Administración local. El conjunto de medidas adoptadas desde el nivel central estatal es el que ha hecho posible esta evolución tan positiva. Los efectos de los comportamientos del pasado y la evolución de los tres últimos años indican la pertinencia de los principios, medidas y bases de la LRSAL para que se puedan garantizar en el futuro las actividades y los servicios públicos locales.

\section{REFLEXIONES FINALES}

La posición tradicional de la Administración local en el sistema político-administrativo español ha sido de subordinación al poder central, sea este el del Estado o, más recientemente, también el de las comunidades autónomas. Esto ha hecho que los servicios públicos más relevantes para los ciudadanos hayan quedado históricamente fuera del ámbito local. Esta situación contrasta con las profundas transformaciones de los gobiernos locales a partir de la década de los 80 del pasado siglo, especialmente en las grandes y medianas ciudades españolas. Estas han tenido que asumir algunas necesidades de sus vecinos al mismo tiempo que se estaban consolidando las comunidades autónomas. El resultado han sido las duplicidades y solapamientos que la reciente crisis ha hecho que aparezcan como insostenibles. Este hecho no debe ocultar que la ciudad sea el lugar natural en donde surgen las necesidades ciudadanas y una buena parte de la innovación social; es en ella donde también de forma natural deben atenderse algunos servicios básicos para garantizar la integración y la cohesión social, la convivencia en comunidad. Para lograr estos objetivos, es preciso un entendimiento entre los diversos niveles territoriales y guiarse por principios como el de subsidiariedad, igualdad, lealtad, solidaridad, eficiencia y efectividad. La reforma emprendida introduce en el régimen local nuevos instrumentos que posibilitan el diálogo necesario entre los distintos poderes territoriales. 
Un tercio de la población española vive en algo más de 7.000 municipios de menos de 20.000 habitantes y accede a las actividades, bienes y servicios públicos en peores condiciones de eficiencia y calidad que los habitantes de las ciudades medianas y grandes españolas. El resultado es una merma real de derechos de estos ciudadanos que debe ser solventada a través de mecanismos de coordinación, integración y cooperación de una manera no necesariamente voluntaria, habida cuenta del insuficiente resultado obtenido hasta ahora cuando se ha dejado a la libre disposición de las partes. De nuevo, se precisa una articulación más adecuada de los poderes territoriales y una mayor implicación, dada su posición en el sistema, de las comunidades autónomas con el fin de que ordenen el territorio de forma más adecuada a las necesidades y derechos de los ciudadanos.

La complejidad de nuestra sociedad aconseja aplicar un enfoque de gobernanza a la autonomía local con el fin de integrar de una manera más efectiva a los numerosos y dinámicos agentes públicos, privados y sociales en la actividad pública local. Para lograrlo es necesario poner mayor énfasis en la colaboración y la gestión participada de esos agentes y que los poderes públicos asuman que ya no es posible satisfacer las necesidades los ciudadanos sin contar con ellos.

La Ley 27/2013, de 27 de diciembre, de racionalización y sostenibilidad de la Administración Local se ha diseñado para preservar el futuro de la Administración local y su estabilidad financiera y competencial; esto es, para garantizar un conjunto de derechos de los ciudadanos respecto a sus municipios. La limitación de las competencias municipales se ha realizado para garantizar su debida financiación y evitar las duplicidades actuales, que provienen de no ajustar las competencias municipales a las transferencias autonómicas, que se cerraron hace más de una década.

La nueva ley ha sido rediseñada desde su origen para que los municipios que se encuentren en una buena situación financiera puedan prestar servicios no obligatorios cuando los obligatorios estén garantizados, no existan duplicidades con las competencias autonómicas y se cumplan los criterios de estabilidad presupuestaria y sostenibilidad financiera. Es decir, para una gran parte de nuestros municipios la situación tras la aprobación de la ley no debería ser sustancialmente distinta a la que venían desarrollando con anterioridad, aunque necesitarán reordenar sus prioridades y acordar con las comunidades autónomas la cartera de servicios no obligatorios, especialmente los servicios sociales. En el caso de los pequeños municipios, la interlocución con las diputaciones provinciales y las comunidades autónomas deberá procurar la sostenibilidad y la garantía de los servicios básicos y una mejor ordenación territorial de estos y de los no obligatorios. Finalmente, la reforma no afecta a la identificación de los ciudadanos con sus pueblos y ciudades, ya que preserva la realidad histórica de su representación democrática.

La profesionalización de la Administración local, esto es, la delimitación clara entre las responsabilidades políticas y las administrativas, es un reto importante para el futuro de los gobiernos locales. El logro del difícil equilibrio entre ambas responsabilidades ha de estar informado por la garantía de la neutralidad y la profesionalización de la acción pública local, que, como sabemos, es determinante en la lucha contra la corrupción. Las medidas de transparencia, de rendición de cuentas y de medición del resultado de los servicios públicos incluidas en la reforma local, sin duda, ayudarán a ese logro.

\section{BIBLIOGRAFÍA}

Arenilla, M. (2011) «Redes de políticas: el caso de la ciudad de Madrid» en Revista Española de Ciencia Política $\mathrm{n}^{\circ} 25$, abril de 2011, p. 31-56.

ARenilla, M., PÉREZ, P. y Romera, O. (2014) «El impacto de la reforma local española en los servicios sociales», en DíAz LEMA, J. M. (Coord.) (2014) Sostenibilidad financiera y Administración local. Valencia: Tirant lo Blanc, p. $185-259$.

ARRoyAl, L. de (1968) [1789] Cartas político-económicas al Conde de Lerena, Estudio preliminar de Antonio Elorza. Madrid: Editorial Ciencia Nueva.

BonNIN J. (1834) Compendio de los Principios de Administración. Madrid: Imprenta de Don José Palacios.

BuRGOS, F. J. de

- (1820) Miscelánea de artes, comercio y literatura. 
- (1978) [1840] Las Ideas de Administración de Javier de Burgos, Estudio preliminar de Eduardo Roca Roca. Alcalá de Henares: INAP.

COLMEIRO, M. (1995) [1850] Derecho Administrativo español. Santiago de Compostela: EGAP.

OLIVÁN, A. (1954) [1843] De la Administración Pública en relación a España. Prólogo de Eduardo García de Enterría. Madrid: IEP.

SÁINZ DE ANDINO, P. (1982) El pensamiento administrativo de Sáinz de Andino. Introducción y notas de José Maa. García Madaria. Madrid: INAP. 